\title{
The Influence of the Ammonolysis Temperature on the Photocatalytic Activity of $\beta$-TaON
}

\author{
Songhak Yoon, ${ }^{1}$ Alexandra E. Maegli, ${ }^{1}$ Santhosh Kumar Matam, ${ }^{1}$ \\ Matthias Trottmann, ${ }^{1}$ Takashi Hisatomi, ${ }^{2}$ Céline Marie Leroy, ${ }^{2}$ Michael Grätzel, ${ }^{2}$ \\ Simone Pokrant, ${ }^{1}$ and Anke Weidenkaff ${ }^{1}$ \\ ${ }^{1}$ Laboratory for Solid State Chemistry and Catalysis, Empa-Swiss Federal Laboratories for Materials Science and Technology, \\ Ueberlandstrasse 129, CH-8600 Duebendorf, Switzerland \\ ${ }^{2}$ Laboratory of Photonics and Interfaces, Ecole Polytechnique Fédérale de Lausanne (EPFL), Station 6, CH-1015 Lausanne, Switzerland \\ Correspondence should be addressed to Anke Weidenkaff; anke.weidenkaff@empa.ch
}

Received 28 November 2012; Accepted 31 January 2013

Academic Editor: Lukas Schmidt-Mende

Copyright (C) 2013 Songhak Yoon et al. This is an open access article distributed under the Creative Commons Attribution License, which permits unrestricted use, distribution, and reproduction in any medium, provided the original work is properly cited.

Phase-pure tantalum oxynitride $\left(\beta\right.$-TaON) powders were synthesized by thermal ammonolysis of $\mathrm{Ta}_{2} \mathrm{O}_{5}$ powders. X-ray diffraction revealed an enlargement of the unit cell and an increase of the crystallite size with increasing ammonolysis temperature. Scanning electron microscopy showed reduced particle sizes for $\beta$-TaON synthesized at 800 and $900^{\circ} \mathrm{C}$ compared to the precursor oxide. With increasing nitridation temperature the Brunauer-Emmett-Teller surface area was reduced and the nitrogen content increased. UVVis spectroscopy showed a bandgap energy of $2.6-2.4 \mathrm{eV}$. The highest oxygen evolution rate of $220 \mu \mathrm{mol} \cdot \mathrm{g}^{-1} \cdot \mathrm{h}^{-1}$ was achieved for $\beta$-TaON synthesized at $800^{\circ} \mathrm{C}$. The factors determining the photocatalytic activity of $\beta$-TaON powders were found to be the specific surface area and defects in the $\beta-\mathrm{TaON}$.

\section{Introduction}

Solar radiation is one of the most promising alternative energy resources to fossil fuels and nuclear power. The conversion of sunlight into electricity or other forms of energy can help to meet future energy needs [1]. However, the production of alternative fuels through the direct utilization of sunlight by photocatalysis or photoelectrochemical (PEC) cells is still far from being marketable as neither acceptable efficiency nor sufficient stability have been demonstrated [24]. To achieve efficient production of hydrogen by solar water splitting several challenges have to be overcome $[5,6]$, in particular, the inefficient absorption of the solar spectrum and the high concentration of defects in photocatalytic material which act as recombination centers for the charge carriers. Since Fujishima and Honda [7] first reported water splitting on a $\mathrm{TiO}_{2}$ electrode in the early 1970s, various concepts of PEC cells have been developed [8-10]. The advantage of $\mathrm{TiO}_{2}$ is its stability and low cost, and the disadvantage is that the low intensity of the solar spectrum in the ultraviolet (UV) can be utilized due to its large bandgap $(\sim 3 \mathrm{eV})$. Materials with a bandgap of around $2.0-2.4 \mathrm{eV}$ are best suited to collect the most intense part of the solar spectrum in the visible light region. This is why oxynitrides are considered as promising semiconductor photoanodes, since the nitridation shifts the bandgap of the oxide to longer wavelengths into the visible light region [11-19]. Especially tantalum oxynitride $(\mathrm{TaON})$ attracted much attention due to its suitable bandgap energy $(2.4-2.5 \mathrm{eV})[20,21]$. Synthesis and crystal structure of $\beta$-TaON were first reported by Brauer and Weidlein [22] followed by additional experimental and theoretical studies on its physical, chemical, and structural properties [23-26]. Hitoki et al. [15] have proven that $\beta$-TaON acts as a stable and efficient photocatalyst for the oxidation of water into $\mathrm{O}_{2}$ under visible light irradiation. Banerjee et al. [27] showed that $\mathrm{TaON}$ nanotube arrays can absorb 
a broad band of the visible light which in turn leads to an enhanced photocurrent. Abe et al. successfully demonstrated efficient overall water splitting with nanogranular $\mathrm{TaON}$ thin films fabricated by electrophoretic deposition of $\beta$-TaON powder and subsequent loading of $\mathrm{IrO}_{2}$ nanoparticles [12]. Recently, TaON photocatalysts modified with $\mathrm{ZrO}_{2}$ [28] or polyaniline [29] exhibited a significant improvement of the photocatalytic activity. Repeatedly, critical factors for the enhancement of photocatalytic $\mathrm{H}_{2}$ and/or $\mathrm{O}_{2}$ evolution reaction have been investigated $[21,30,31]$. The density and distribution of defects, crystal size, surface area, surface morphology, and cocatalyst loading have been found to be decisive factors. Since the efficiency of the catalyst is governed by a complicated interplay between bulk and surface properties, the control of morphology, surface area, crystallinity, and defect concentration via a tailored synthesis procedure is essential for the improvement of the photocatalytic activities in $\beta$-TaON.

TaON can be obtained by annealing $\mathrm{Ta}_{2} \mathrm{O}_{5}$ in an ammonia $[22,23]$. However, the synthesis of phase-pure $\beta$-TaON is a particularly challenging task. Small variations in the synthesis procedure often lead to undesirable nitrogenrich phases or polymorphs of TaON. For instance, $\mathrm{Ta}_{3} \mathrm{~N}_{5}$ can be easily formed when $\mathrm{Ta}_{2} \mathrm{O}_{5}$ reacts with gaseous ammonia in the temperature range of $700^{\circ} \mathrm{C}-900^{\circ} \mathrm{C}$ [23] suggesting that the temperature is one of the most important experimental parameters that determines the resulting composition of the compounds. Apart from the chemical composition, the particle size, crystallinity, and surface area are affected by the ammonolysis conditions. Therefore, the objective of this study is to synthesize phase-pure $\beta$-TaON by thermal ammonolysis and to tune the surface area, the amount of nitrogen-incorporation, and the crystal size in order to improve the photocatalytic activity without using precious metals as a cocatalyst. To this end, the influence of the ammonolysis temperature on the crystal structure, microstructure, nitrogen content, and bandgap energy of $\beta$ TaON was studied to identify the best synthesis conditions. Systematic comparison of the experimental results obtained by various techniques is expected to provide insight into the particularly crucial factors for the photocatalytic activity of $\beta$-TaON.

\section{Experimental Procedures}

A series of tantalum oxynitride $(\beta-\mathrm{TaON})$ powders was synthesized by thermal ammonolysis of crystalline $\mathrm{Ta}_{2} \mathrm{O}_{5}$ powder (Fluka, 99.9\%) in a tubular bed reactor using flowing $\mathrm{NH}_{3}$ (Messer, $\geq 99.98 \%$ ) at different temperatures $\left(800,850,900,950\right.$, and $\left.1000^{\circ} \mathrm{C}\right)$. Around $3 \mathrm{~g}$ of the white $\mathrm{Ta}_{2} \mathrm{O}_{5}$ powder were heated $\left(20^{\circ} \mathrm{C} / \mathrm{min}\right)$ to the desired temperature in an $\mathrm{NH}_{3}$ stream $(15-20 \mathrm{~mL} / \mathrm{min})$ and the ammonolysis was carried out for $16.5 \mathrm{~h}$. Subsequently, the oxynitride samples were cooled down to room temperature in the same $\mathrm{NH}_{3}$ stream. At $800^{\circ} \mathrm{C}$ a prolonged ammonolysis reaction time of $68 \mathrm{~h}$ was required to achieve the complete transformation into the phase-pure tantalum oxynitride.
X-ray diffraction (XRD) patterns were obtained using a PANalytical X'Pert PRO $\theta-2 \theta$ scan system equipped with a Johansson monochromator and an X'Celerator linear detector. The incident X-rays had a wavelength of $1.5406 \AA$ $\left(\mathrm{Cu}-\mathrm{K} \alpha_{1}\right)$. The diffraction patterns were recorded from $20^{\circ}$ to $100^{\circ}(2 \theta)$ with an angular step of $0.0167^{\circ}$. XRD patterns were analyzed by the Le Bail method [32] integrated in the program Fullprof [33] to determine the lattice parameters. The crystal sizes are calculated by Scherrer equation [34]. The Thompson-Cox-Hastings pseudo-Voigt function [35] was chosen as profile function and the background was modeled with a sixth-order polynomial function. The instrumental contribution to peak broadening was estimated by measuring the standard reference sample $\mathrm{CeO}_{2}$ (NIST SRM674b).

A scanning electron microscope (SEM, LEO JSM-6300F) was used for microstructure analysis. The Brunauer-EmmettTeller (BET) surface area of the powders was determined by $\mathrm{N}_{2}$ physisorption at the temperature of liquid nitrogen $\left(-196^{\circ} \mathrm{C}\right)$. Thermal reoxidation studies with thermogravimetric analysis (TGA) were carried out with a NETZSCH STA 409 CD thermobalance. Around $50 \mathrm{mg}$ of the $\beta-\mathrm{TaON}$ powders were heated in an alumina crucible at a heating rate of $10^{\circ} \mathrm{C} / \mathrm{min}$ up to $1500^{\circ} \mathrm{C}$ in synthetic air $(50 \mathrm{~mL} / \mathrm{min})$. $\mathrm{UV}$-visible diffuse reflectance spectra were collected using a UV-Vis spectrophotometer (UV-3600 Shimadzu UV-VIS NIR) equipped with an integrating sphere. Spectra were recorded in the range of 200 to $1200 \mathrm{~nm}$. The Kubelka-Munk conversion was applied to the obtained reflectance spectra and the bandgap wavelength was estimated by extrapolating the absorption onset wavelength to the wavelength axis.

Photocatalytic reactions were performed in a closed constant-volume system connected to a gas chromatograph. A $150 \mathrm{~W}$ halogen lamp (Osram, HLX 64640) was used as a light source. $0.1 \mathrm{~g} \beta$-TaON and $0.2 \mathrm{~g} \mathrm{La}_{2} \mathrm{O}_{3}$ powders were dispersed in an aqueous $\mathrm{AgNO}_{3}$ solution $(0.01 \mathrm{M}, 250 \mathrm{~mL})$. $\mathrm{La}_{2} \mathrm{O}_{3}$ was used as a buffer to maintain the $\mathrm{pH}$ of the solution at around 8 during the reaction [18] and the $\mathrm{Ag}^{+}$ ions were employed as sacrificial electron acceptors for $\mathrm{O}_{2}$ evolution. The reaction system was made of gas-tight glass and evacuated sufficiently to remove air. Before light illumination, 100 mbar of He was introduced into the reaction system to suppress vaporization of water. Accordingly, the leakage of atmospheric oxygen was prevented during the $\mathrm{O}_{2}$ evolution reaction.

\section{Results and Discussion}

$\mathrm{X}$-ray diffraction (XRD) patterns of $\beta$-TaON powders synthesized at different temperatures $\left(800^{\circ} \mathrm{C}, 850^{\circ} \mathrm{C}, 900^{\circ} \mathrm{C}\right.$, $950^{\circ} \mathrm{C}$, and $1000^{\circ} \mathrm{C}$ ) are shown in Figure 1(a). All observed reflections were assigned to pure $\beta$-TaON (JCPDS-PDF 710178) and no diffraction peaks arising from any secondary phases or impurities were detected. It is well known that $\mathrm{Ta}_{3} \mathrm{~N}_{5}$ can be easily formed as a secondary phase, when dry $\mathrm{NH}_{3}$ gas is used in the ammonolysis. In this study, it was essential to apply a low flow rate of dry $\mathrm{NH}_{3}(15-20 \mathrm{~mL} / \mathrm{min})$ in order to obtain phase-pure $\beta$-TaON phases. Whenever the flow rate exceeds $20 \mathrm{~mL} / \mathrm{min}, \mathrm{Ta}_{3} \mathrm{~N}_{5}$ and/or polymorphs 


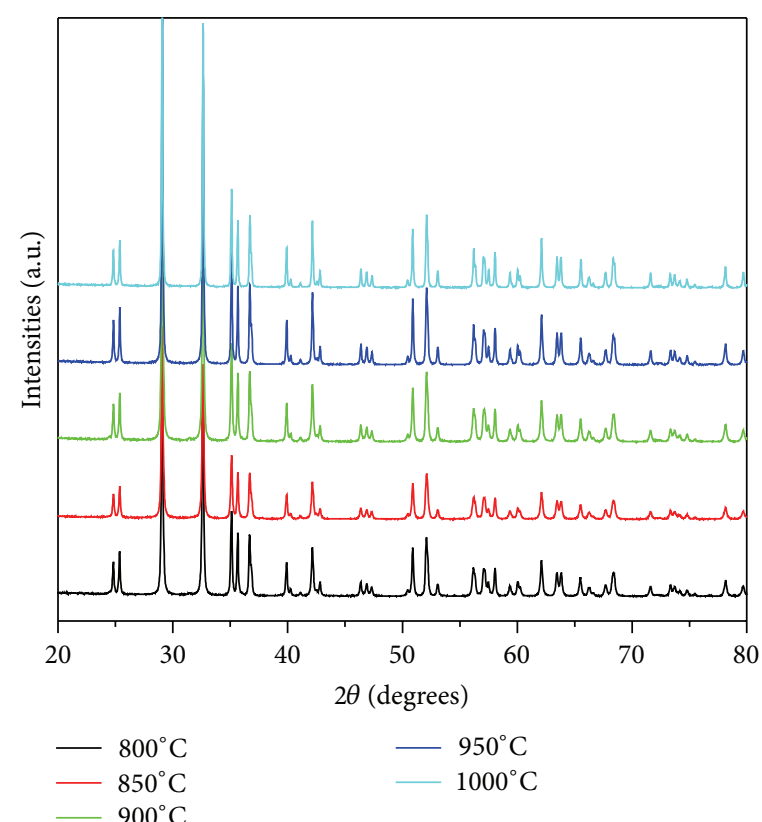

(a)

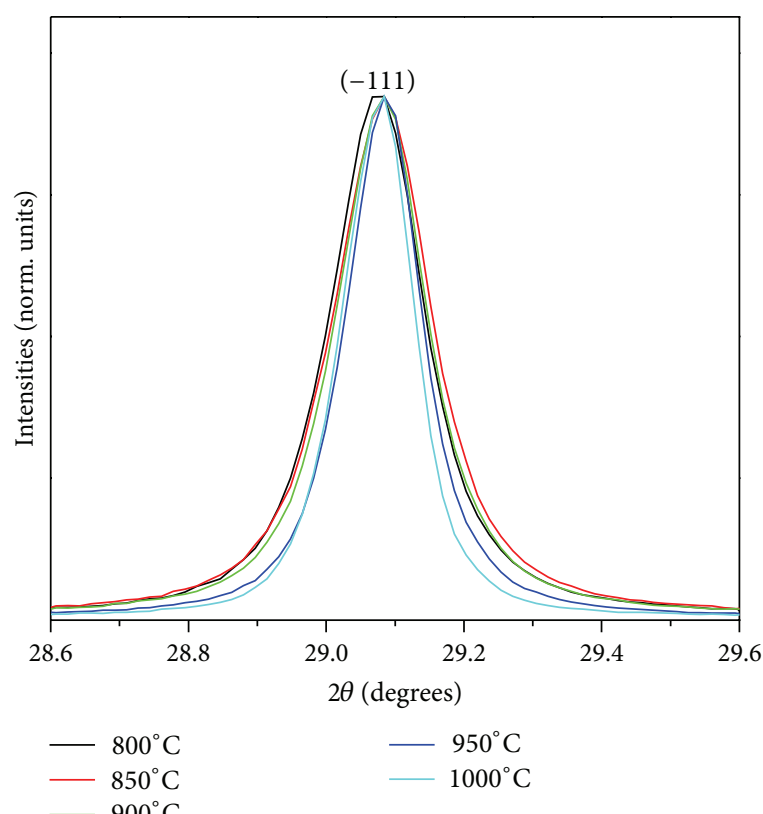

(b)

FIgURE 1: X-ray diffraction patterns of the $\beta$-TaON powders.

of TaON were often found as secondary phases. The full width at half maximum (FWHM) of the reflections decreased with increasing ammonolysis temperature mainly due to the crystal growth. An exception to this is $\beta$-TaON synthesized at $800^{\circ} \mathrm{C}$ (Figure 1(b)) where the ammonolysis was conducted for $68 \mathrm{~h}$. The prolonged reaction time leads to a reduction of the FWHM thus an increase of the crystal size.

Figure 3 shows SEM images of $\beta-\mathrm{TaON}$. The size of individual particles of the precursor oxide $\mathrm{Ta}_{2} \mathrm{O}_{5}$ was less than $1 \mu \mathrm{m}$ and the surface of the particles was rather smooth. After ammonolysis at $800^{\circ} \mathrm{C}$ and $900^{\circ} \mathrm{C}$, pores were observed on the surface of $\beta-\mathrm{TaON}$ particles and the particle size was reduced compared to the precursor oxide. Increasing the ammonolysis temperature to $1000^{\circ} \mathrm{C}$ led again to a smoothing of the surface due to sintering. These observations are consistent with the BET surface area of the powders (Table 2). The BET surface area of the starting substance $\mathrm{Ta}_{2} \mathrm{O}_{5}$ was $3.5 \mathrm{~m}^{2} / \mathrm{g}$. With increasing ammonolysis temperature the surface area first increased going through a maximum at $850^{\circ} \mathrm{C}$ and eventually decreased again. The powder synthesized at $800^{\circ} \mathrm{C}$ shows a slightly lower specific surface area (SSA) compared to that at $850^{\circ} \mathrm{C}$. The lower SSA of samples prepared at $1000^{\circ} \mathrm{C}$ compared to the precursor oxide is attributed to the sintering of $\beta$-TaON particles.

The XRD pattern and Le Bail fitting profile of the exemplarily selected $\beta$-TaON powder synthesized at $1000^{\circ} \mathrm{C}$ are presented in Figure 2. The difference plot of observed and calculated diffraction profiles is shown together with the Bragg positions. The Le Bail fitting results for the cell parameters of $\beta-\mathrm{TaON}$ as a function of temperature are listed in Table 1. A monoclinic crystal structure with space group $P 2_{1} / c$ was identified. With increasing ammonolysis temperature, the lattice parameters $b, c$, and $\beta$ gradually

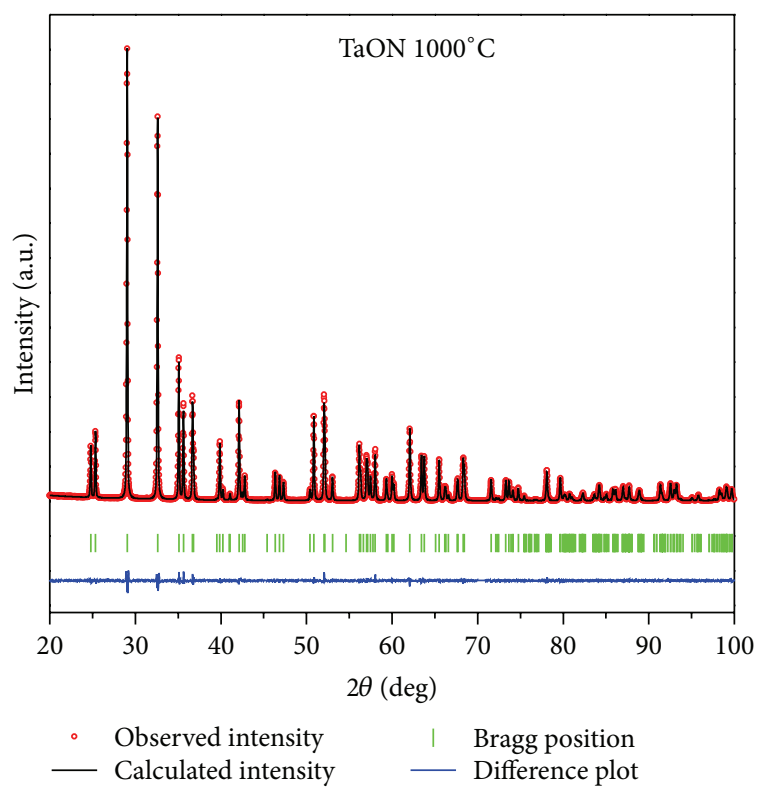

FIGURE 2: XRD pattern and Le Bail fitting profile of the $\beta$-TaON powder synthesized at $1000^{\circ} \mathrm{C}$. The difference plot of the observed and calculated diffraction profile is shown together with the Bragg positions represented by short vertical markers.

increase resulting in an expanded unit-cell volume. Since the anionic radius of nitrogen is larger than that of oxygen, the unit-cell expansion gives indirect evidence that more nitrogen is incorporated into the crystal lattice of $\beta-\mathrm{TaON}$ with increasing ammonolysis temperature. Interestingly, the lattice parameter $a$ decreased with increasing ammonolysis 
TABLE 1: Crystal structure parameters of $\beta$-TaON powders derived from Le Bail fitting results.

\begin{tabular}{|c|c|c|c|c|c|c|c|c|c|}
\hline $\begin{array}{l}\text { Temperature } \\
\left({ }^{\circ} \mathrm{C}\right)\end{array}$ & $\begin{array}{c}\text { Lattice } \\
\text { parameter } \\
a(\AA)\end{array}$ & $\begin{array}{c}\text { Lattice } \\
\text { parameter } \\
b(\AA)\end{array}$ & $\begin{array}{l}\text { Lattice } \\
\text { parameter } \\
c(\AA)\end{array}$ & $\begin{array}{c}\text { Lattice } \\
\text { parameter } \\
\beta\left(^{\circ}\right)\end{array}$ & $\begin{array}{l}\text { Unit-cell } \\
\text { volume } \\
\quad\left(\AA^{3}\right)\end{array}$ & $R_{p}$ & $R_{\mathrm{wp}}$ & $R_{\exp }$ & $\chi^{2}$ \\
\hline $800^{\mathrm{a}}$ & $4.96732(5)$ & $5.03494(5)$ & $5.18281(5)$ & 99.6097 (4) & $127.804(2)$ & 5.87 & 8.03 & 4.11 & 3.82 \\
\hline 850 & $4.96737(5)$ & $5.03549(5)$ & $5.18332(6)$ & $99.6242(4)$ & $127.826(2)$ & 5.71 & 7.67 & 4.56 & 2.83 \\
\hline 900 & $4.96713(5)$ & $5.03563(5)$ & $5.18339(5)$ & $99.6280(3)$ & $127.829(2)$ & 5.52 & 7.64 & 3.85 & 3.94 \\
\hline 950 & $4.96695(4)$ & $5.03599(4)$ & $5.18381(4)$ & $99.6357(3)$ & $127.836(2)$ & 5.33 & 7.35 & 3.94 & 3.48 \\
\hline 1000 & $4.96631(3)$ & $5.03640(3)$ & $5.18494(3)$ & $99.6621(2)$ & $127.848(1)$ & 5.21 & 7.45 & 4.31 & 2.99 \\
\hline
\end{tabular}

Nitridation for $68 \mathrm{~h}$.

Space group symmetry: $P 2_{1} / c$.

Numbers in parentheses are standard deviations

$R_{p}, R_{\mathrm{wp}}, R_{\mathrm{exp}}$, and $\chi^{2}$ are the reliability factors and goodness-of-fit, respectively.

TABLE 2: Crystallite size, specific surface area (SSA), nitrogen content, band gap, and $\mathrm{O}_{2}$ evolution rate for $\beta$-TaON powders synthesized at different nitridation temperatures.

\begin{tabular}{lccccc}
\hline $\begin{array}{l}\text { Temperature } \\
\left({ }^{\circ} \mathrm{C}\right)\end{array}$ & $\begin{array}{c}\text { Crystallite } \\
\text { size }^{\mathrm{a}}(\mathrm{nm})\end{array}$ & $\begin{array}{c}\mathrm{SSA} \\
\left(\mathrm{m}^{2} / \mathrm{g}\right)\end{array}$ & $\begin{array}{c}\mathrm{N} /(\mathrm{N}+\mathrm{O})^{\mathrm{b}} \\
\text { ratio }\end{array}$ & $\begin{array}{c}\text { Band gap }^{\mathrm{c}}(\mathrm{eV}) \\
\left(\mu \mathrm{mol}^{2} \cdot \mathrm{g}^{-1} \cdot \mathrm{h}^{-1}\right)\end{array}$ \\
\hline $800^{\mathrm{d}}$ & $58.73(9)$ & 6.6 & 0.400 & 2.6 & 220 \\
850 & $55.36(5)$ & 7.5 & 0.396 & 2.5 & 2.5 \\
900 & $55.81(6)$ & 6.2 & 0.406 & 2.5 & 130 \\
950 & $72.08(6)$ & 3.2 & 0.420 & 2.4 & 50 \\
1000 & $73.58(7)$ & 3.2 & 0.436 & 20 & 2.4 \\
\hline
\end{tabular}

a Calculated by Scherrer equation with the Rietveld refinement.

${ }^{\mathrm{b}}$ Obtained by TGA.

${ }^{c}$ Estimated by extrapolating the onset of absorption to the wavelength axis from UV-visible diffuse reflectance spectra.

${ }^{\mathrm{d}}$ Nitridation for $68 \mathrm{~h}$.
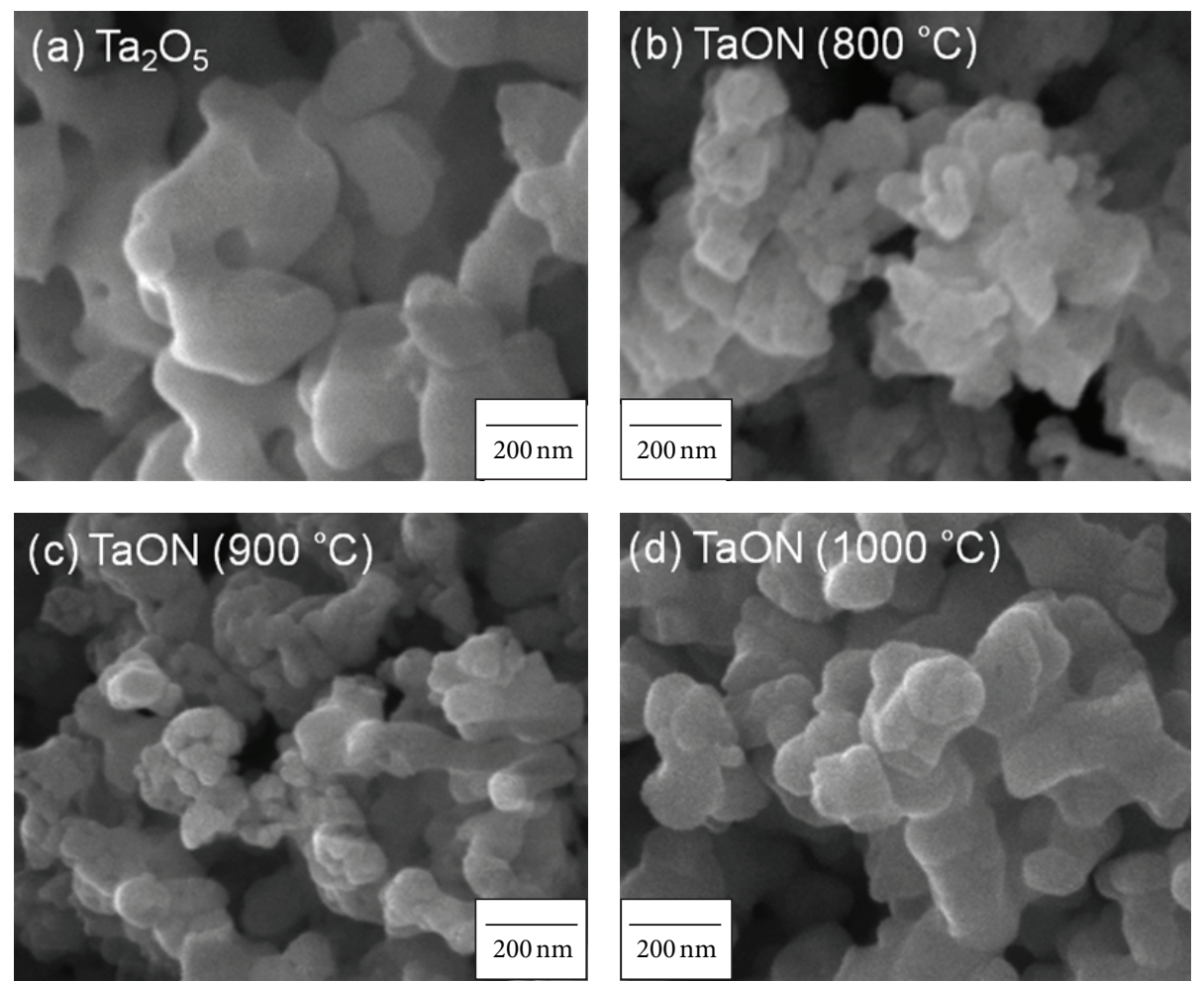

Figure 3: Scanning electron micrographs (SEMs) of the precursor $\mathrm{Ta}_{2} \mathrm{O}_{5}$ and $\beta$ - $\mathrm{TaON}$ powders synthesized at $800^{\circ} \mathrm{C}, 900^{\circ} \mathrm{C}$, and $1000^{\circ} \mathrm{C}$, respectively. 
temperature. Our fitting results show that with increasing ammonolysis temperature the unit-cell expands along the $y$ and $z$-axis. Yashima et al. [36] explained similar findings with complete occupational ordering of oxygen and nitrogen in alternating layers normal to the [100] direction in $\beta-\mathrm{TaON}$. Using Rietveld refinement of the neutron and synchrotron Xray diffraction patterns, they found that oxygen and nitrogen atoms in $\beta$-TaON are coordinated with three and four tantalum atoms $\left(\mathrm{OTa}_{3}\right.$ and $\left.\mathrm{NTa}_{4}\right)$, respectively. The structure exhibits a stacking of alternative $\mathrm{NTa}_{4}$ and $\mathrm{OTa}_{3}$ layers. With the increasing degree of substitution, crystallographically favored positions in the $\mathrm{NTa}_{4}$ layers are filled with more nitrogen resulting in an anisotropic expansion of the unit cell. The mechanism, however, leading to the observed crystallographic anisotropy is not yet fully understood and remains to be elucidated. The crystallite sizes were calculated based on the Scherrer equation with the Rietveld refinement and they are summarized in Table 2 . The average size increases with increasing ammonolysis temperature. $\beta$-TaON synthesized at $800^{\circ} \mathrm{C}$ shows a slightly larger crystal size compared to those obtained at 850 and $900^{\circ} \mathrm{C}$, since the ammonolysis time was extended.

Thermal stability and nitrogen content of the oxynitride powders were determined by TGA during a reoxidation process. Figure 4 illustrates the weight gain and loss upon heating of the oxynitride powders in synthetic air. All samples were thermally stable up to around $400^{\circ} \mathrm{C}$ at least. Above this temperature, the uptake of oxygen leads to gradual mass increase up to $750^{\circ} \mathrm{C}$ followed by a sharp increase peaking at $850^{\circ} \mathrm{C}$. The subsequent mass loss above $850^{\circ} \mathrm{C}$ is attributed to the release of nitrogen which is commonly observed in oxynitrides during the reoxidation process $[37,38]$. It should be mentioned that the nitrogen is already released gradually as $\mathrm{N}_{2}$ during the uptake of oxygen which otherwise could not be incorporated into the lattice [33]. In many reoxidation reactions, a dinitrogen adduct intermediate phase is formed between the original oxynitride and the final oxide [39]. It explains a higher weight than that of the final oxide due to nitrogen retention [39-41]. The intermediate phase is stable in a certain temperature range during reoxidation before it converts into the oxide. Interestingly, in this study no stable intermediate phase was found. Instead, a sharp mass increase peaking at $850^{\circ} \mathrm{C}$ was observed. XRD proved the reoxidized powder to be identical to the precursor oxide $\mathrm{Ta}_{2} \mathrm{O}_{5}$. The amount of nitrogen in $\beta$-TaON was estimated from the weight gain $\Delta m$ during the reoxidation. The calculated nitrogen content representing the ratio of nitrogen to the sum of oxygen and nitrogen is given in Table 2 . It increased with increasing ammonolysis temperature indicating an enhanced nitridation at elevated temperatures excluding the powder synthesized at $800^{\circ} \mathrm{C}$.

Figure 5 shows UV-visible diffuse reflectance spectra of the oxynitrides and the precursor oxide. The absorption edge wavelength of the precursor oxide $\mathrm{Ta}_{2} \mathrm{O}_{5}$ is in the UV region at $310 \mathrm{~nm}$ (bandgap energy $E_{g}=4.0 \mathrm{eV}$ ). Thermal ammonolysis causes a redshift of the absorption edge into the visible light region. With increasing temperature the absorption edge shifted to longer wavelengths resulting in bandgap energies of 2.6 to $2.4 \mathrm{eV}$ which differs only marginally

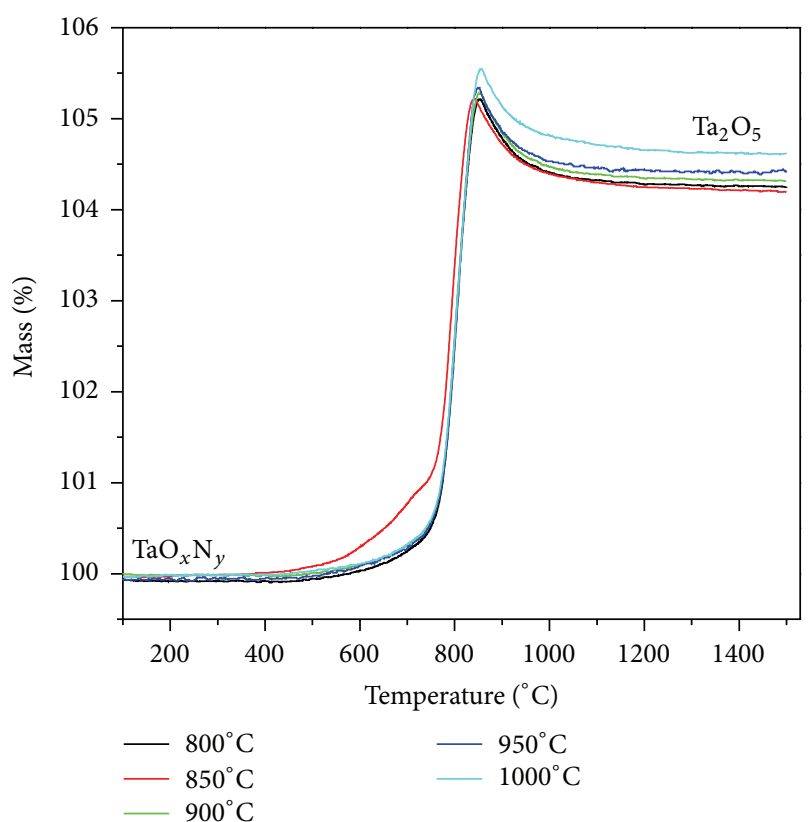

FIgURE 4: Thermogravimetric analysis (TGA) of the synthesized $\beta$ TaON powders.

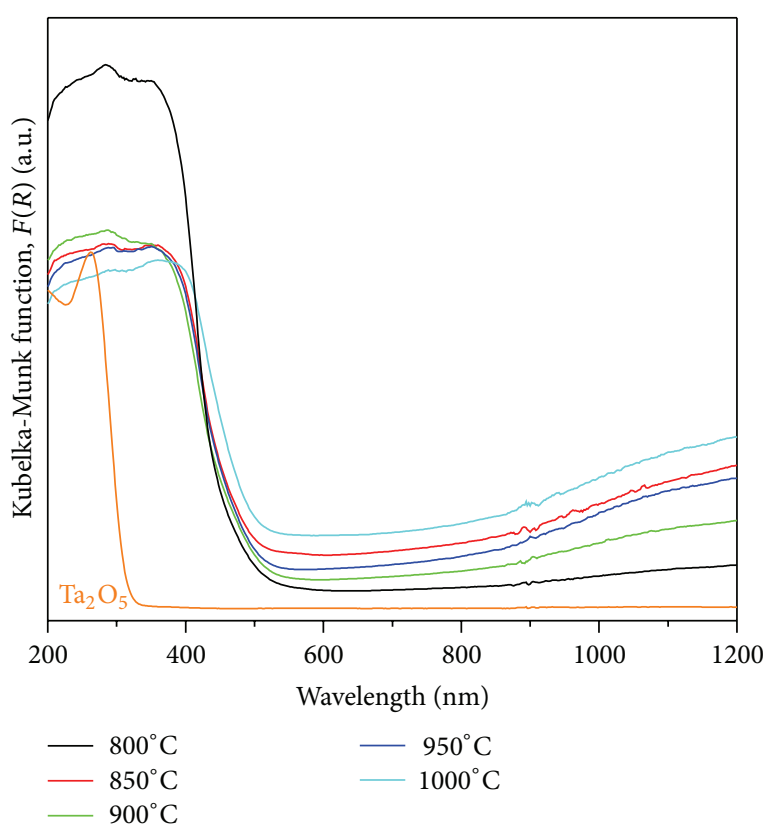

Figure 5: UV-visible diffuse reflectance spectra of the $\beta$-TaON powders.

from previous reports $[15,20]$. This finding is also in good agreement with the reoxidation study which showed that the nitrogen content increases with increasing ammonolysis temperature. Consequently the color of the $\beta$-TaON powders gradually changes from green yellowish to dark green. Furthermore, the background absorption at wavelengths above the absorption edge increases with increasing temperature, with the exception of $\beta$-TaON synthesized at $850^{\circ} \mathrm{C}$. This 
indicates temperature-dependent generation of defects in $\beta$ TaON due to reduced tantalum and/or anionic vacancies $[18,37,42]$. However, it is not yet clear why $\beta$-TaON synthesized at $850^{\circ} \mathrm{C}$ has a higher background level than the samples synthesized at 900 and $950^{\circ} \mathrm{C}$.

The oxygen evolution rate as a function of the ammonolysis temperature is shown in Figure 6 and Table 2. The highest rate of $220 \mu \mathrm{mol} \cdot \mathrm{g}^{-1} \cdot \mathrm{h}^{-1}$ was obtained for $\beta$-TaON synthesized at $800^{\circ} \mathrm{C}$. The reference substance $\mathrm{TiO}_{2}$ (Degussa, P-25) showed a rate of $70 \mu \mathrm{mol} \cdot \mathrm{g}^{-1} \cdot \mathrm{h}^{-1}$ under the same experimental conditions. With increasing ammonolysis temperature the oxygen evolution rate of $\beta$-TaON drastically decreased to negligible values. Unfortunately the photocatalytic activity of $\beta$-TaON presented in this study cannot be compared directly to previous findings $[15,31]$, because they have not been performed exactly in same conditions.

Important factors influencing the photo- and catalytic activity of $\beta$-TaON are given in Table 2: crystallite size, surface area, nitrogen content, bandgap, bandgap position, and oxidizing strength of the valence band are the determining factors for oxygen evolution rate. The data in Table 2 exhibit general trends: with increasing ammonolysis temperature crystallite and particle sizes increase, while the surface area of the $\beta$-TaON powders decreases due to sintering processes. Furthermore, the increasing nitrogen content is correlated with a lowering of the bandgap energy, as expected. Chun et al. [20] have reported that the top of valence band in $\mathrm{TaON}$ is far lower than the water oxidation potential, indicating that the valence band position does not largely affect the photocatalytic water oxidation activity. In general, the water oxidation activity of $\beta$-TaON is governed by all these factors. The drastic loss of the catalytic activity at higher temperatures shows that factors like the increasing crystallite size and the bandgap shift into the red by increased $\mathrm{N}$ incorporation do not have a major influence in our case, since these effects are believed to increase the activity rather than decreasing it. Obviously, factors known for leading to a reduction of the catalytic activity dominate in our case. These variables are the reduced surface area and the increased defect concentration with increasing temperature. The highest oxygen evolution rate with $220 \mu \mathrm{mol} \cdot \mathrm{g}^{-1} \cdot \mathrm{h}^{-1}$, however, was obtained with $\beta$ $\mathrm{TaON}$ synthesized at $800^{\circ} \mathrm{C}$ followed closely by $\beta$-TaON synthesized at $850^{\circ} \mathrm{C}\left(200 \mu \mathrm{mol} \cdot \mathrm{g}^{-1} \cdot \mathrm{h}^{-1}\right)$ featuring the largest surface area among all samples with $7.5 \mathrm{~m}^{2} / \mathrm{g}$. Large surface areas are generally known to have a positive influence on the photocatalytic activity, since the number of active sites scale in first approximation with the surface area. Hence we explain the excellent activity observed at $800^{\circ} \mathrm{C}$ with the combination of high surface area and low defect concentration. At $850^{\circ} \mathrm{C}$, however, the beneficial effect of a large surface area is counterbalanced by a high defect concentration leading to comparable, but slightly reduced, activity. This indicates that surface area and defect concentration are of equal importance for the catalytic activity in our system.

In conclusion, the small differences in the average crystal size and/or the bandgap do not influence significantly the photocatalytic activity of $\beta$-TaON. A possible reason could be that these quantities were not changed by the temperature

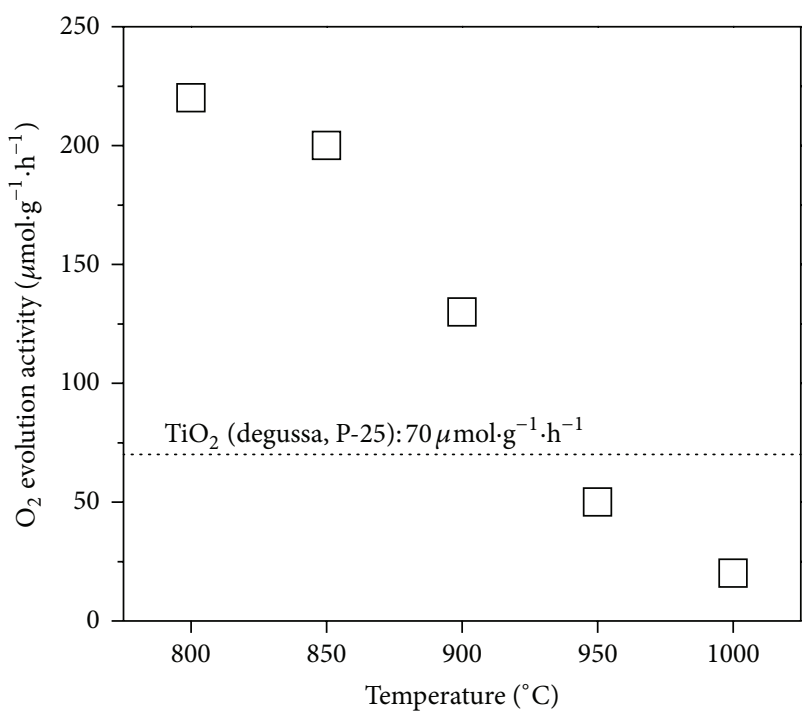

FIgURE 6: $\mathrm{O}_{2}$ evolution rate of the $\beta$-TaON powders as a function of the nitridation temperature. $0.1 \mathrm{~g} \beta$-TaON dispersed in an aqueous $\mathrm{AgNO}_{3}$ solution was irradiated with a $150 \mathrm{~W}$ halogen lamp.

variation in the synthesis condition on such a large scale that their influence on the catalytic activity would be measurable. Our experiments show that a high surface area and a minimal defect concentration improve the catalytic activity of $\beta-\mathrm{TaON}$ and can be optimized by adapting the synthesis conditions.

\section{Summary}

$\beta$-TaON powders were successfully synthesized at different temperatures by thermal ammonolysis of the precursor oxide $\mathrm{Ta}_{2} \mathrm{O}_{5}$. All samples were characterized structurally as well as chemically, and the associated photocatalytic activities were measured. Defect concentration and surface area were found to be the main factors to have an essential influence on the photocatalytic activities of $\beta$-TaON. An improvement by a factor of three in the oxygen evolution rate was obtained versus a reference measurement on $\mathrm{TiO}_{2}$ by tuning the synthesis condition of $\beta-\mathrm{TaON}$.

\section{Conflict of Interests}

The authors declare no conflict of interests.

\section{Acknowledgment}

This research has been funded by the European Commission (Project NanoPEC, contract number 227179).

\section{References}

[1] A. J. Nozik and J. Miller, "Introduction to solar photon conversion," Chemical Reviews, vol. 110, no. 11, pp. 6443-6445, 2010.

[2] A. Kudo and Y. Miseki, "Heterogeneous photocatalyst materials for water splitting," Chemical Society Reviews, vol. 38, no. 1, pp. 253-278, 2009. 
[3] O. Khaselev and J. A. Turner, "A monolithic photovoltaicphotoelectrochemical device for hydrogen production via water splitting," Science, vol. 280, no. 5362, pp. 425-427, 1998.

[4] M. G. Walter, E. L. Warren, J. R. McKone et al., "Solar water splitting cells," Chemical Reviews, vol. 110, no. 11, pp. 6446-6473, 2010.

[5] A. J. Bard and M. A. Fox, "Artificial photosynthesis: solar splitting of water to hydrogen and oxygen," Accounts of Chemical Research, vol. 28, no. 3, pp. 141-145, 1995.

[6] A. J. Bard, G. M. Whitesides, R. N. Zare, and F. W. Mclafferty, "Holy grails in chemistry," Accounts of Chemical Research, vol. 28, no. 3, pp. 91-91, 1995.

[7] A. Fujishima and K. Honda, "Electrochemical photolysis of water at a semiconductor electrode," Nature, vol. 238, no. 5358, pp. 37-38, 1972.

[8] M. Grätzel, "Photoelectrochemical cells," Nature, vol. 414, no. 6861, pp. 338-344, 2001.

[9] M. C. Hanna and A. J. Nozik, "Solar conversion efficiency of photovoltaic and photoelectrolysis cells with carrier multiplication absorbers," Journal of Applied Physics, vol. 100, no. 7, Article ID 074510, 2006.

[10] B. O’Regan and M. Grätzel, "A low-cost, high-efficiency solar cell based on dye-sensitized colloidal $\mathrm{TiO}_{2}$ films," Nature, vol. 353, no. 6346, pp. 737-740, 1991.

[11] C. Le Paven-Thivet, A. Ishikawa, A. Ziani et al., "Photoelectrochemical properties of crystalline perovskite lanthanum titanium oxynitride films under visible light," Journal of Physical Chemistry C, vol. 113, no. 15, pp. 6156-6162, 2009.

[12] R. Abe, M. Higashi, and K. Domen, "Facile fabrication of an efficient oxynitride TaON photoanode for overall water splitting into $\mathrm{H}_{2}$ and $\mathrm{O}_{2}$ under visible light irradiation," Journal of the American Chemical Society, vol. 132, no. 34, pp. 11828-11829, 2010.

[13] K. Maeda, K. Teramura, D. Lu et al., "Photocatalyst releasing hydrogen from water," Nature, vol. 440, no. 7082, p. 295, 2006.

[14] R. Asahi, T. Morikawa, T. Ohwaki, K. Aoki, and Y. Taga, "Visible-light photocatalysis in nitrogen-doped titanium oxides," Science, vol. 293, no. 5528, pp. 269-271, 2001.

[15] G. Hitoki, T. Takata, J. N. Kondo, M. Hara, H. Kobayashi, and K. Domen, "An oxynitride, TaON, as an efficient water oxidation photocatalyst under visible light irradiation $(\lambda \leq 500 \mathrm{~nm})$," Chemical Communications, no. 16, pp. 1698-1699, 2002.

[16] M. Hara, G. Hitoki, T. Takata, J. N. Kondo, H. Kobayashi, and K. Domen, " $\mathrm{Ta}_{3} \mathrm{~N}_{5}$ and $\mathrm{TaON}$ as novel photocatalysts responding to visible light," Studies in Surface Science and Catalysis, vol. 145, pp. 169-172, 2002.

[17] S. Ito, K. R. Thampi, P. Comte, P. Liska, and M. Grätzel, "Highly active meso-microporous $\mathrm{TaON}$ photocatalyst driven by visible light," Chemical Communications, no. 2, pp. 268-270, 2005.

[18] A. Kasahara, K. Nukumizu, G. Hitoki et al., "Photoreactions on $\mathrm{LaTiO}_{2} \mathrm{~N}$ under visible light irradiation," Journal of Physical Chemistry A, vol. 106, no. 29, pp. 6750-6753, 2002.

[19] K. Maeda and K. Domen, "New non-oxide photocatalysts designed for overall water splitting under visible light," Journal of Physical Chemistry C, vol. 111, no. 22, pp. 7851-7861, 2007.

[20] W. Chun, A. Ishikawa, H. Fujisawa et al., "Conduction and valence band positions of $\mathrm{Ta}_{2} \mathrm{O}_{5}, \mathrm{TaOn}$, and $\mathrm{Ta}_{3} \mathrm{~N}_{5}$ by UPS and electrochemical methods," Journal of Physical Chemistry B, vol. 107, no. 8, pp. 1798-1803, 2003.

[21] M. Hara, T. Takata, J. N. Kondo, and K. Domen, "Photocatalytic reduction of water by $\mathrm{TaON}$ under visible light irradiation," Catalysis Today, vol. 90, no. 3-4, pp. 313-317, 2004.
[22] G. Brauer and J. R. Weidlein, "Synthesis and properties of tantalum oxide nitride TaON," Angewandte Chemie International Edition, vol. 4, no. 10, p. 875, 1965.

[23] J. H. Swisher and M. H. Read, "Thermodynamic properties and electrical conductivity of $\mathrm{Ta}_{3} \mathrm{~N}_{5}$ and TaON," Metallurgical Transactions, vol. 3, no. 2, pp. 489-494, 1972.

[24] D. Armytage and B. E. F. Fender, "Anion ordering in TaONpowder neutron-diffraction investigation," Acta Crystallographica Section B, vol. 30, no. 3, pp. 809-812, 1974.

[25] M. Weishauptand and J. Strahle, "Preparation of oxide nitrides VON, NbON, and TaON-crystal-structure of NbON and TaON," Zeitschrift für Anorganische und Allgemeine Chemie, vol. 429, no. 1, pp. 261-269, 1977.

[26] C. M. Fang, E. Orhan, G. A. de Wijs et al., "The electronic structure of tantalum (oxy)nitrides $\mathrm{TaON}$ and $\mathrm{Ta}_{3} \mathrm{~N}_{5}$," Journal of Materials Chemistry, vol. 11, no. 4, pp. 1248-1252, 2001.

[27] S. Banerjee, S. K. Mohapatra, and M. Misra, "Synthesis of TaON nanotube arrays by sonoelectrochemical anodization followed by nitridation: a novel catalyst for photoelectrochemical hydrogen generation from water," Chemical Communications, no. 46, pp. 7137-7139, 2009.

[28] S. S. K. Ma, K. Maeda, and K. Domen, "Modification of $\mathrm{TaON}$ with $\mathrm{ZrO}_{2}$ to improve photocatalytic hydrogen evolution activity under visible light: influence of preparation conditions on activity," Catalysis Science \& Technology, vol. 2, no. 4, pp. 818823,2012

[29] J. Hou, Z. Wang, R. Cao, S. Jiao, and H. Zhu, "Preparation of polyaniline modified $\mathrm{TaON}$ with enhanced visible light photocatalytic activities," Dalton Transactions, vol. 40, no. 16, pp. 4038-4041, 2011.

[30] K. Maeda, H. Terashima, K. Kase, M. Higashi, M. Tabata, and K. Domen, "Surface modification of TaON with monoclinic $\mathrm{ZrO}_{2}$ to produce a composite photocatalyst with enhanced hydrogen evolution activity under visible light," Bulletin of the Chemical Society of Japan, vol. 81, no. 8, pp. 927-937, 2008.

[31] K. Maeda, R. Abe, and K. Domen, "Role and function of ruthenium species as promoters with $\mathrm{TaON}$-based photocatalysts for oxygen evolution in two-step water splitting under visible light," Journal of Physical Chemistry C, vol. 115, no. 7, pp. 3057-3064, 2011.

[32] Le Bail, Duroy, and Fourquet, "Ab-initio structure determination of $\mathrm{LiSbWO}_{6}$ by X-ray powder diffraction," Materials Research Bulletin, vol. 23, no. 3, pp. 447-452, 1988.

[33] J. Rodríguez-Carvajal, "Recent advances in magnetic structure determination by neutron powder diffraction," Physica B, vol. 192, no. 1-2, pp. 55-69, 1993.

[34] P. Scherrer, "Inteferenzen an regellos orientierten Teilchen im Rontgenlicht," Nachrichten von der Gesellschaft der Wissenschaften zu Göttingen, Mathematisch-Physikalische Klasse, vol. 2, pp. 98-100, 1918.

[35] P. Thompson, D. E. Cox, and J. B. Hastings, "Rietveld refinement of Debye-Scherrer synchrotron X-ray data from $\mathrm{Al}_{2} \mathrm{O}_{3}$," Journal of Applied Crystallography, vol. 20, pp. 79-83, 1987.

[36] M. Yashima, Y. Lee, and K. Domen, "Crystal structure and electron density of tantalum oxynitride, a visible light responsive photocatalyst," Chemistry of Materials, vol. 19, no. 3, pp. 588593, 2007.

[37] A. Rachel, S. G. Ebbinghaus, M. Güngerich et al., "Tantalum and niobium perovskite oxynitrides: synthesis and analysis of the thermal behaviour," Thermochimica Acta, vol. 438, no. 1-2, pp. 134-143, 2005. 
[38] A. Maegli, S. Yoon, E. Otal, L. Karvonen, P. Mandaliev, and A. Weidenkaff, "Perovskite-type $\operatorname{SrTi}_{1-x} \mathrm{Nb}_{x}(\mathrm{O}, \mathrm{N})_{3}$ compounds: synthesis, crystal structure and optical properties," Journal of Solid State Chemistry, vol. 184, no. 4, pp. 929-936, 2011.

[39] D. Logvinovich, L. Bocher, D. Sheptyakov et al., "Microstructure, surface composition and chemical stability of partly ordered $\mathrm{LaTiO}_{2}$ N," Solid State Sciences, vol. 11, no. 8, pp. 15131519, 2009.

[40] Le Gendre, Marchand, and Laurent, "A new class of inorganic compounds containing dinitrogen-metal bonds," Journal of the European Ceramic Society, vol. 17, no. 15-16, pp. 1813-1818, 1997.

[41] D. Logvinovich, S. G. Ebbinghaus, A. Reller, I. Marozau, D. Ferri, and A. Weidenkaff, "Synthesis, crystal structure and optical properties of $\mathrm{LaNbON}_{2}$," Zeitschrift für Anorganische und Allgemeine Chemie, vol. 636, no. 6, pp. 905-912, 2010.

[42] V. N. Kuznetsov and N. Serpone, "On the origin of the spectral bands in the visible absorption spectra of visible-light-active $\mathrm{TiO}_{2}$ specimens analysis and assignments," Journal of Physical Chemistry C, vol. 113, no. 34, pp. 15110-15123, 2009. 

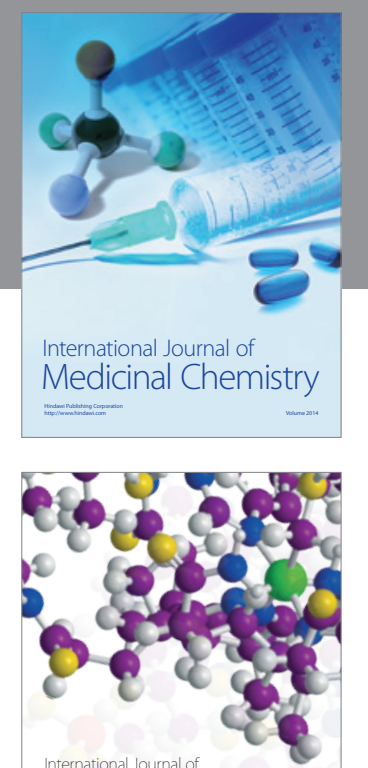

\section{Carbohydrate} Chemistry

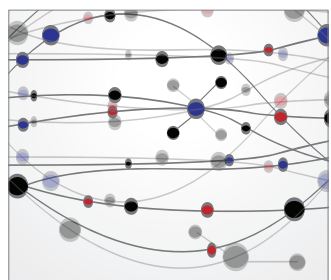

The Scientific World Journal
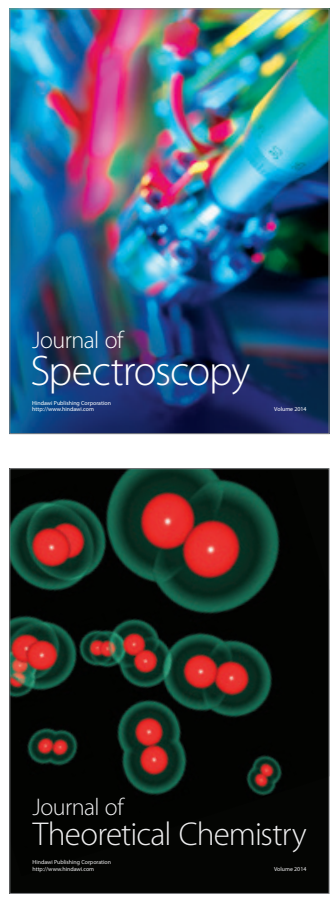
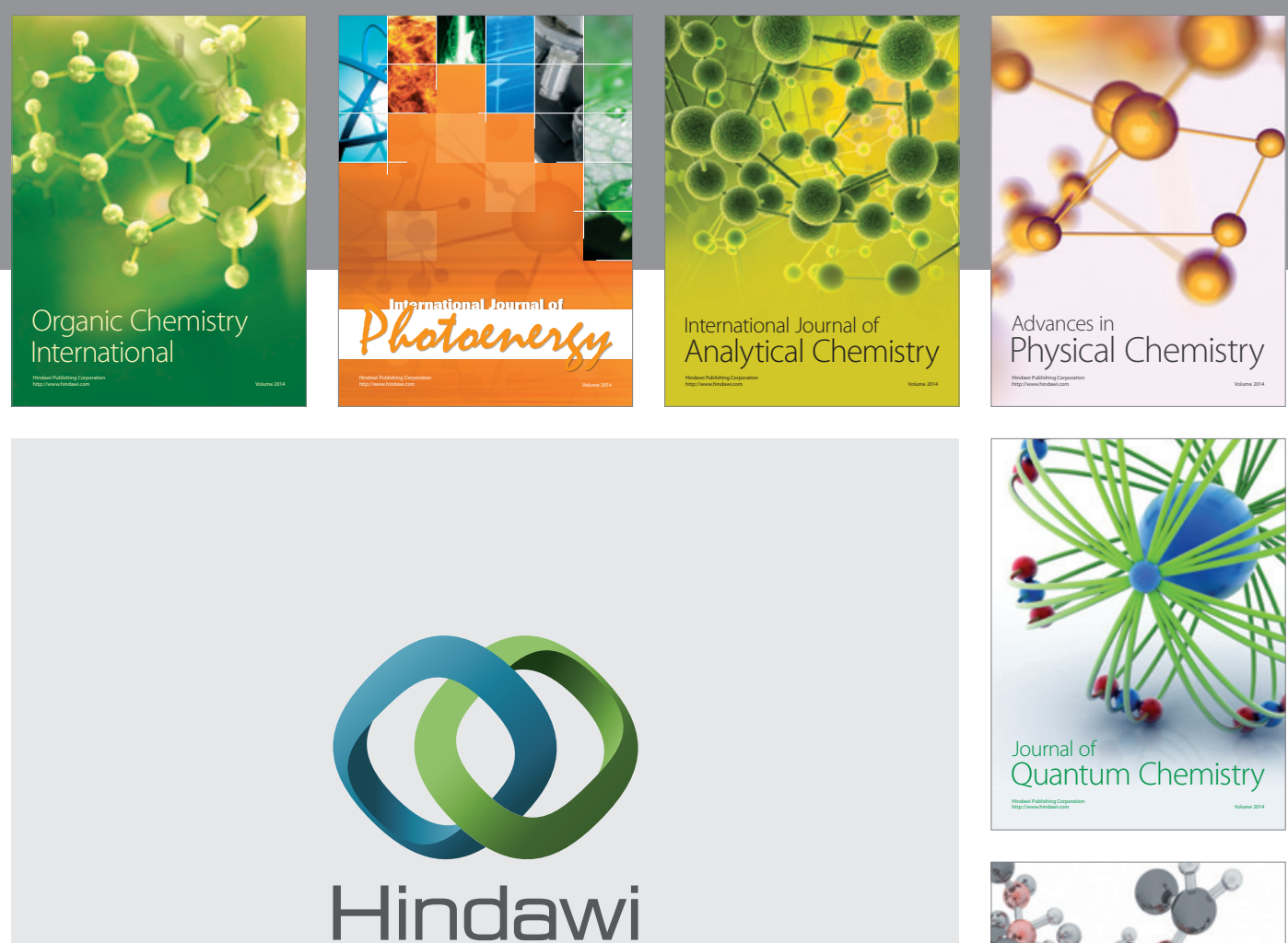

Submit your manuscripts at

http://www.hindawi.com

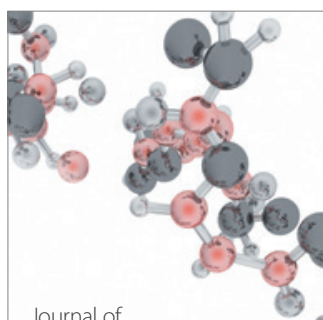

Analytical Methods

in Chemistry

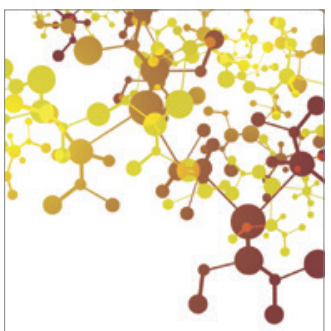

Journal of

Applied Chemistry

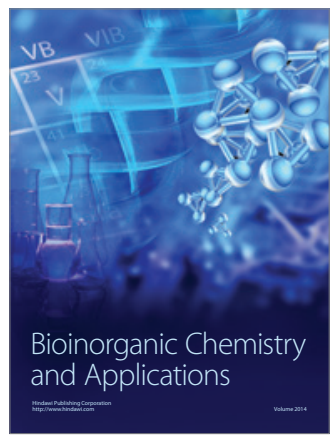

Inorganic Chemistry
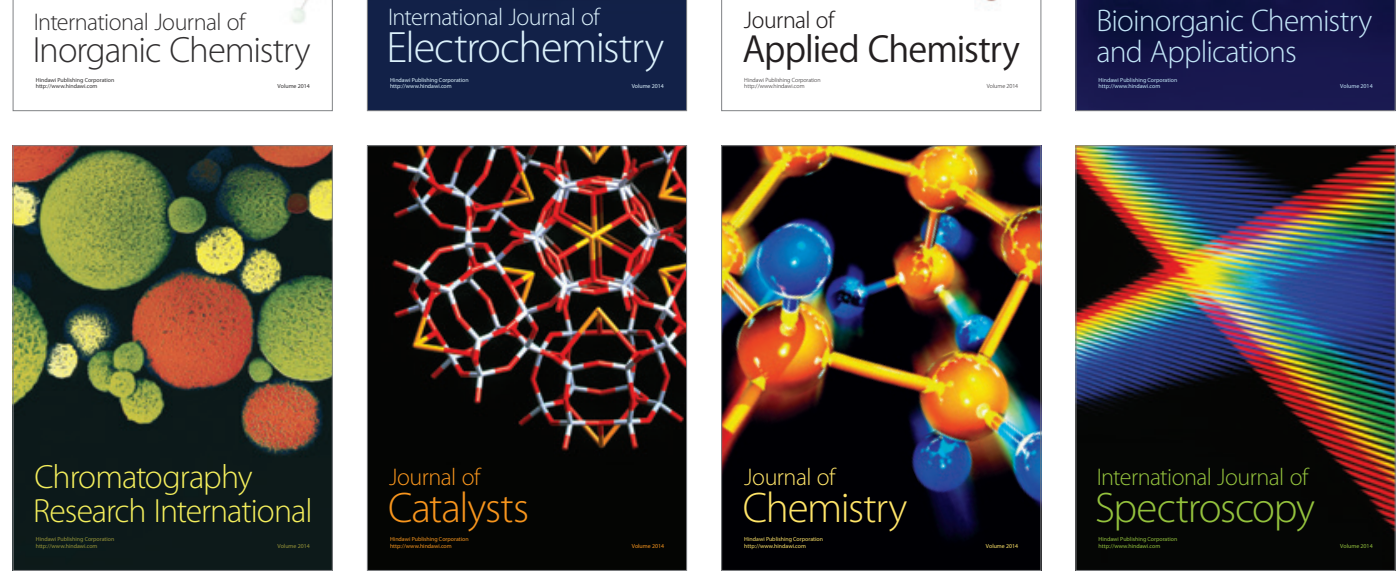